\title{
ACCESO A LA JUSTICIA DE MUJERES VÍCTIMAS DE VIOLENCIA SEXUAL CON DISCAPACIDAD. REFLEXIÓN EN EL CONTEXTO COLOMBIANO
}

Alexandra Milena Chaparro López

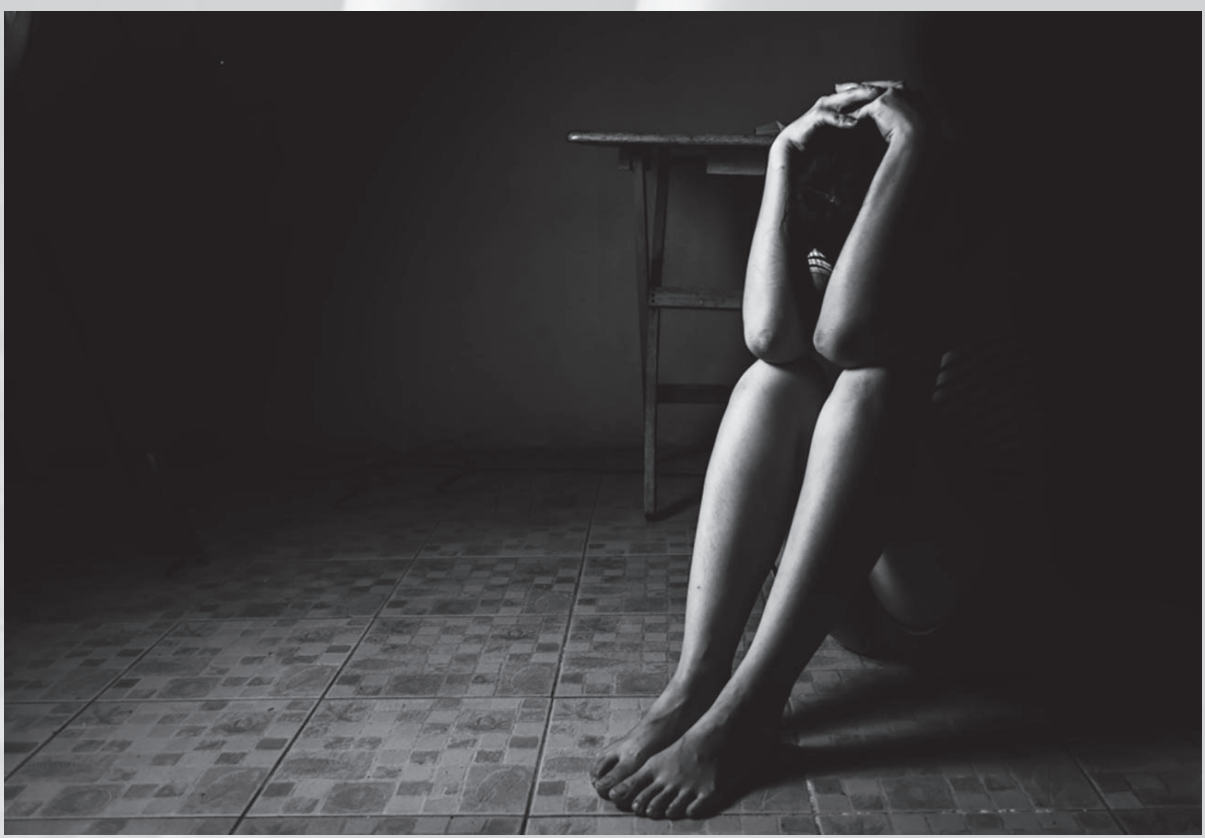





\title{
ACCESO A LA JUSTICIA DE MUJERES VÍCTIMAS DE VIOLENCIA SEXUAL CON DISCAPACIDAD. REFLEXIÓN EN EL CONTEXTO COLOMBIANO
}

\author{
Alexandra Milena Chaparro lópez \\ UNIVERSIDAD DEL ROSARIO
}

\section{Resumen}

El presente artículo explora el papel de la justicia frente a la violencia sexual contra la mujer con discapacidad en el marco del conflicto armado y el postconflicto colombiano; además, genera una reflexión acerca de la debilidad del Estado para hacer efectivo el goce de sus derechos. En la primera parte se exponen algunos elementos que introducen al/la lector/a sobre el fenómeno de la violencia sexual contra las mujeres; posteriormente se aborda el tema de acceso a la justicia como ejercicio de la ciudadanía, así como los elementos claves de la debida diligencia por parte del Estado. Asimismo, se retoman algunos elementos que hacen evidentes los obstáculos con los cuales se enfrentan las mujeres vulneradas y se realiza un análisis sobre la impunidad existente en el contexto colombiano evidenciado mediante reportes estadísticos que dan cuenta del subregistro y escasa información por parte de entidades gubernamentales sobre el tema. De igual modo, se hace una revisión frente a las acciones de Entidades Estatales, tales como la Fiscalía General de la Nación, la Defensoría del Pueblo, la Unidad para atención y reparación integral a las víctimas, la Consejería Presidencial para los Derechos Humanos y el Ministerio de Justicia, para garantizar el ejercicio efectivo de los derechos de estas mujeres, dados los programas que desarrollan esas entidades con enfoque diferencial de mujer y discapacidad, así como los datos estadísticos e informes de seguimiento recientes sobre la población en condición de discapacidad atendida por dichas entidades.

Palabras clave: discapacidad, violencia sexual, acceso a la justicia, impunidad, derechos humanos, conflicto armado, posconflicto.

La autora: maestranda en Derechos Humanos de la Universidad del Rosario. Correo electrónico: alexandrachaparrol@gmail.com

Recibido: 5 de mayo 5 2018; evaluado: 7 de agosto de 2018; aceptado: 21 de agosto de 2018. 


\title{
RIGHT OF ACCESS TO JUSTICE FOR WOMEN WITH DISABILITIES, VICTIMS OF SEXUAL HARASSMENT, IN THE COLOMBIAN CONTEXT
}

\author{
Alexandra Milena Chaparro López \\ UNIVERSIDAD DEL ROSARIO
}

\begin{abstract}
This article aims to explore the role of authorities in the face of sexual harassment against women with disabilities in the context of the Colombian armed conflict and post-conflict. Additionally, it presents a critical reflection on the weakness of the government to enforce women's rights. The first part of the paper outlines some elements that introduce the reader to the phenomenon of sexual violence against women. Subsequently, the issue of access to justice as an exercise of citizenship is addressed, as well as the key elements of due diligence by the State. Likewise, some elements that evidence the obstacles faced by affected women are taken up again and an analysis is made of the current climate of impunity in Colombia, evidenced through statistical reports that account for the underreporting and scarce information on the part of government entities on the subject. Similarly, the actions of State Entities are reviewed, such as the Office of the Attorney General of the Nation, Ombudsman's Office, Unit for Integral Attention and Reparation of Victims, Presidential Counsel for Human Rights and Ministry of Justice, to guarantee the effective exercise of women's rights, through programs developed by these entities with a differential focus on women and disability. The paper utilizes statistical data and recent monitoring reports about the population with disabilities assisted by the mentioned entities.
\end{abstract}

Keywords: disability, sexual harassment, access to justice, impunity, human rights, armed conflict, post-conflict.

About the author: Student of a Masters Degree on Human Rights at the Universidad del Rosario. Email: alexandrachaparrol@gmail.com

Received: May 5, 2018; reviewed: August 7, 2018; accepted: August 21, 2018 


\section{Introducción}

Hablar de acceso a la justicia y atención a víctimas de violencia sexual implica hacer una revisión sobre las condiciones de vulnerabilidad que afrontan las mujeres en el marco del conflicto armado y posconflicto. Al abordar las estadísticas que dan cuenta de la realidad del fenómeno de la violencia sexual en contra de las mujeres con discapacidad durante esos dos períodos en Colombia, se encuentra que se han mantenido tasas críticas de ocurrencia de ataques contra su integridad personal y sexual. Sin embargo, las cifras existentes dificultan dimensionar la gravedad del daño. Los datos reales de mujeres colombianas víctimas de violencia sexual, reflejo del abuso, muestran un subregistro, ${ }^{1}$ que ha sido sistemático y generalizado - lo que se constituye en un delito de lesa humanidad-y que se suma a los demás crímenes cometidos en el conflicto armado. Al respecto, Barragán y Alfonso afirman:

Pese a los datos estadísticos analizados, los informes cualitativos presentados por las instituciones respecto de sus avances en materia de respuesta a las Violencias Contra las Mujeres y de los informes internacionales revisados, se tiene la certeza de la existencia de un gran subregistro de este problema social, que, a todas luces, aún requiere de un esfuerzo grande del Estado, la familia y la sociedad para ser superado. ${ }^{2}$

El panorama resulta aún más desolador si se tiene en cuenta que, en cinco décadas de conflicto armado, la sexual fue un tipo de violencia que se "normalizó" y se convirtió en un proceso de invisibilización cobijado por una mirada indiferente. Asimismo, las personas en condición de discapacidad fueron expuestas a la discriminación y vulneración de sus derechos:

Algunas de estas personas, han vivido con una discapacidad toda su vida. Otras, han adquirido una discapacidad como causa de un conflicto bélico. Estas personas, se encuentran entre las más escondidas y olvidadas de entre las personas desplazadas. Se encuentran excluidas de los servicios de asistencia

\footnotetext{
Organización de Estados Americanos [OEA], "Las mujeres frente a la violencia y la discriminación derivadas del conflicto armado en Colombia", http://www.cidh.org/countryrep/colombiamujeres06sp/informe\%20 mujeres\%20colombia\%202006\%20espanol.pdf (acceso agosto 1, 2014).

2 Fanny Barragán Ávila y Martha Alfonso, "Lineamientos de política pública para la prevención, protección, atención y sanción de las violencias basadas en género y contra las mujeres en Colombia", http://historico. equidadmujer.gov.co/Normativa/PoliticaPublica/LineamientosPolitica.pdf (acceso junio 7, 2014).
} 
generales, o simplemente no pueden acceder, como consecuencia de la existencia de barreras actitudinales, físicas y sociales. ${ }^{3}$

Las mujeres en situación de discapacidad se encuentran con una serie de obstáculos que les imposibilita acceder a la justicia, debido a la falta de garantías legales.

Frente a esta realidad surge la pregunta que esta reflexión buscó resolver: en el marco del proceso de posconflicto en Colombia, para garantizar el ejercicio efectivo de los derechos, ¿las condiciones de mujer y discapacidad determinan la calidad y efectividad en el acceso a la justicia de las mujeres víctimas de violencia sexual en el país, resultado del conflicto armado?

Se recurrió a la metodología documental, para verificar qué ha sucedido ante la dinámica de la violencia sexual en contra de las mujeres en condición de discapacidad durante dos períodos que han marcado la historia del país: conflicto armado y posconflicto (2008-2015 y 2016-2018) y el acceso a la justicia.

\section{La violencia sexual}

La violencia que afectó a Colombia, producto del conflicto armado, tuvo un claro impacto diferenciado por género, debido a que las mujeres fueron sometidas a distintas formas de violación de sus derechos humanos. La violencia sexual constituyó una práctica recurrente en escenarios de guerra; así lo expresan las Naciones Unidas en el informe de la relatora especial sobre la violencia contra la mujer: "[...] la violencia contra la mujer en especial la de carácter sexual por parte de grupos armados, resulta habitual en el contexto de un conflicto". ${ }^{4}$

Se construyó un catálogo de crímenes sexuales en contra de las mujeres para exponer la degradación de la confrontación bélica, aunque se cometen sin distinción de sexo u origen étnico. ${ }^{5}$

3 Beatriz Martínez Ríos, "Pobreza, discapacidad y derechos humanos", Revista Española de Discapacidad 1, núm. 1 (2013): 12.

4 Organización de Naciones Unidas [ONU], "Integración de los derechos humanos de la mujer y la perspectiva de género. Violencia contra la mujer. Informe de la relatora especial sobre la violencia contra la mujer, sus causas y consecuencias, Sra. Radhika Coomarasswam, presentado de conformidad con la resolución 2001/49 de la Comisión de Derechos Humanos. Adición. Misión a Colombia (1 a 7 de noviembre de 2001)", http:// www.hchr.org.co/documentoseinformes/documentos/html/informes/onu/resvm/E-CN-4-2002-83-Add3. html (acceso agosto 1 de 2014).

5 ONU, "Integración de los derechos humanos de la mujer y la perspectiva de género". 
La Corporación Sisma Mujer afirma que la Corte Constitucional, en el Auto 092 de 2008, puso en evidencia la debilidad del Estado colombiano para prevenir y proteger a las mujeres frente a la violencia sexual, además del desacatamiento de las recomendaciones formuladas a la Nación colombiana por parte de la Corte Interamericana de Derechos Humanos y la relatora especial de las Naciones Unidas sobre la violencia contra la mujer. ${ }^{6}$

El papel de la justicia es sumamente importante; sin embargo, a pesar de los pronunciamientos de la Corte Constitucional acerca de las barreras en el acceso a la justicia para mujeres víctimas de violencia sexual, de la insistencia ante la Fiscalía General de la Nación para la adopción de las medidas necesarias para asegurar el avance de las investigaciones y el inicio de procedimientos investigativos respecto a los hechos victimizantes, estos no fueron objeto de atención por parte de la justicia ordinaria.

\section{Acceso a la justicia como ejercicio de la ciudadanía}

La Declaración de los derechos humanos, en su Artículo 8, define que todos los seres humanos pueden acceder al sistema judicial cuando sean lesionados sus derechos. La Convención para la eliminación de todas las formas de discriminación contra la mujer en su Artículo 2, literal c, alude a la responsabilidad que le corresponde a cada Estado de proveer a hombres y mujeres el amparo judicial por medio de las instancias destinadas para ello.

Estas acepciones fortalecen la importancia que cobra la noción de ciudadanía y su desarrollo pleno para poder acceder a la justicia, ya que es un elemento indispensable que permite la realización de todos los demás derechos y que es "sine qua non para el ejercicio ciudadano". ${ }^{7}$

El papel de la justicia debe responder de manera positiva, garantista y con la debida diligencia contra la discriminación a las mujeres a la luz del principio democrático; ello exige que el Estado y sus operadores se abstengan de cometer cualquier acto de violación contra los derechos humanos y actúen de forma

6 Corporación Sisma Mujer, "Obstáculos para acceso a la justicia de las mujeres víctimas de violencia sexual en Colombia", http://www.sismamujer.org/wp-content/uploads/2016/12/33.-Obst\%C3\%Alculos-de-Acceso-a-Justicia-de-Mujeres-V\%C3\%ADctimas-de-Violencia-Sexual-en-Colombia.pdf (acceso agosto 2, 2014). Nina Ferrer Araujo, "El acceso a la justicia como elemento indispensable del ejercicio de la ciudadanía femenina”, Opinión Jurídica 9, núm. 17 (2010): 117. 
acuciosa con el fin de prevenir, investigar y sancionar cualquier abuso en contra de población vulnerable, como las mujeres en condición de discapacidad y proveer formas de erradicación de obstáculos a la justicia. ${ }^{8}$

El acceso a entornos equitativos debe ser abordado desde diversas perspectivas ${ }^{9}$ que abarquen la real apropiación de los convenios internacionales; la coherencia y puesta en marcha del ordenamiento jurídico en relación con el derecho internacional; la capacitación pertinente de actores clave del sistema jurídico nacional, con base en las recomendaciones expuestas por el Comité para la eliminación de la discriminación contra la mujer; la adopción efectiva de medidas que permitan corregir las desigualdades históricamente manifiestas; indemnización y reparación de víctimas de actos de violencia; la efectividad en el uso de alternativas para las mujeres, que garanticen un entorno de paz, y la formulación de programas locales y nacionales para la protección de las mujeres víctimas. ${ }^{10}$

La Comisión Interamericana de Derechos Humanos (CIDH) ha puesto de manifiesto el prioritario desafío en los sistemas de protección de derechos humanos en ámbitos nacionales e internacionales frente al derecho de la mujer y su garantía de espacios libres de violencia y discriminación. ${ }^{11}$ Ello obedece a que las mujeres tienen derecho a un acceso adecuado a la justicia y a los recursos judiciales para investigar, sancionar y reparar las violencias ocurridas en su contra, así como a evitar cualquier acto de discriminación por razones de género; por eso, las comunidades deben gozar de igualdad de condiciones, puesto que tales derechos son inherentes al ser humano. ${ }^{12}$

8 Silvia Ribotta, "Reglas de Brasilia sobre acceso a la justicia de las personas en condición de vulnerabilidad. Vulnerabilidad, pobreza y acceso a la justicia", ponencia presentada en la XIV cumbre judicial iberoamericana, Brasilia, 4 a 6 de marzo, 2008.

9 Natalia Barbero, "Los derechos humanos de la mujer y la violencia sexual en el derecho internacional", Principia Iuris 17, núm. 17 (2012): 359

10 Corporación Humanas, Aportes para el acceso a la justicia de las mujeres en Colombia (Bogotá: Antropos, 2011), 37.

11 Víctor Abramovich, "De las violaciones masivas a los patrones estructurales: nuevos enfoques y clásicas tensiones en el Sistema Interamericano de Derechos Humanos", Derecho PUCP 63 (2009): 24. http://revistas. pucp.edu.pe/index.php/derechopucp/article/download/2961/2863 (acceso octubre 15, 2014)

12 Comisión Interamericana de Derechos Humanos, "Acceso a la justicia para mujeres víctimas de violencia en las Américas", https://www.cidh.oas.org/pdf\%20files/Informe\%20Acceso\%20a\%20la\%20Justicia\%20 Espanol\%20020507.pdf (acceso agosto 1, 2014); Roxana Arroyo Vargas, "Acceso a la justicia para las mujeres... el laberinto androcéntrico del derecho", Revista IIDH 53 (2011): 39, http://www.corteidh.or.cr/ tablas/r26673.pdf (acceso mayo 5, 2014). 
La adopción de esas medidas efectivas y alternativas que conduzcan a la igualdad de derechos se estableció a partir de los principios generales para la implementación de los acuerdos de paz, en los que se tuvo en cuenta el enfoque de género:

2.3.7. [...] El Gobierno Nacional y las FARC-EP rechazan cualquier forma de discriminación contra la mujer y reafirman que el aporte de las mujeres como sujetos políticos en la vida pública es vital para el fortalecimiento de la democracia y para el mantenimiento y el fomento de la paz. En la implementación de todo lo acordado en el punto 2 del presente Acuerdo se garantizará el enfoque de género. ${ }^{13}$

A partir de esa nueva perspectiva de enfoque de género, es importante reflexionar acerca de cómo han asumido la justicia y sus operadores las denuncias por estos hechos, pues se requiere:

[... profundizar la reflexión sobre el papel de la justicia en la transformación de los patrones socioculturales de inferioridad, incapacidad y subordinación que confluyen como factores causales de las diversas violencias y de las diferentes formas de discriminación, y contribuye a la identificación de prácticas reflejadas en la actuación de los operadores de justicia que reproducen las dinámicas sociales de subvaloración, tolerancia y abuso, y que, en últimas, integran ese conjunto amplio de obstáculos psicosociales y sociojurídicos que las mujeres, enfrentan cuando se relacionan con el Estado a través de la demanda de justicia. ${ }^{14}$

No solo se trata de las reformas en materia normativa, sino de la manera en la que tanto víctimas como victimarios y la sociedad reconozcan que el daño no se debe solo a la comisión del delito, sino a la omisión y al silencio, pues lo que se logrará será acrecentar y encubrir esa realidad. ${ }^{15}$

13 Gobierno Nacional y Fuerzas Armadas Revolucionarias de Colombia-Ejército del Pueblo, "Acuerdo final para la terminación del conflicto y la construcción de una paz estable y duradera", http://www.altocomisionadoparalapaz.gov.co/herramientas/Documents/Acuerdo-Final-AF-web.pdf (acceso octubre 5, 2018).

14 Fundación Círculo de Estudios Culturales y Políticos Colombia, Defensoría del Pueblo y Organización Internacional para las Migraciones [OIM], El papel del acceso a la justicia en la superación de la discriminación hacia las mujeres, los niños, las niñas y adolescentes (Bogotá: OIM, 2013), 29.

15 Sandra Milena Franco Moreno y Marlings Eugenia Garcés Ballesteros, "Políticas de equidad para las mujeres víctimas de violencia en Santander", Revista al derecho y al revés 8 (2013): 61, http://publicaciones.unisangil. edu.co/index.php/revista-derecho-reves/article/download/35/39 
Las mujeres en condición de discapacidad se hallan relegadas de la esfera de participación y, por eso, del acceso a la justicia:

Es frecuente que las personas con discapacidad apenas tengan voz en el proceso democrático. Incluso cuando se hacen oír, no necesariamente se las escucha. La falta de participación en el debate político puede dar lugar a que se formulen políticas sin la intervención activa de los grupos que con más probabilidad se verán afectados por su resultado. Llevando a su aislamiento respecto de los procesos democráticos y escepticismo acerca de la posibilidad de que se les haga justicia en aplicación de la ley. ${ }^{16}$

La Encuesta de prevalencia de violencia sexual en contra de las mujeres en el contexto del conflicto armado colombiano (2010-2015), desarrollada por Oxfam con el apoyo de mujeres y catorce organizaciones de derechos humanos de todo el país, ${ }^{17}$ evidenció el porcentaje y las instituciones a las que acudieron las mujeres víctimas de violencia sexual en el marco del conflicto armado para denunciar, aunque no se informa acerca de condición de discapacidad (Tabla 1):

Tabla 1. Instituciones a las que recurrieron las víctimas para denunciar

\begin{tabular}{|l|l|}
\hline Fiscalía & 51,06 \\
\hline Defensoría & 5,37 \\
\hline Inspección de Policía & 14,92 \\
\hline Instituto Colombiano de Bienestar Familiar & 1,26 \\
\hline Comisaría de Familia & 18,57 \\
\hline Personería & 0,74 \\
\hline Sin información & 8,08 \\
\hline Total (universo representado) & 161.767 \\
\hline
\end{tabular}

Fuente: Campaña Violaciones y otras violencias: saquen mi cuerpo de la guerra, "Encuesta de prevalencia de violencia sexual en contra de las mujeres en el contexto del conflicto armado colombiano 2010-2015", http://humanidadvigente. net/wp-content/uploads/2017/08/Encuesta-de-prevalencia-de-violencia-sexual-CSCG.pdf (acceso octubre 5, 2018).

16 Gerard Quinn y Theresia Degener, "Derechos humanos y discapacidad. Uso actual y posibilidades futuras de los instrumentos de derechos humanos de las Naciones Unidas en el contexto de la discapacidad", http://repositoriocdpd.net:8080/bitstream/handle/123456789/614/L_QuinnG_DerechosHumanosDiscapacidad_2002.pdf?sequence=1 (acceso agosto 2, 2014).

17 Campaña Violaciones y otras violencias: saquen mi cuerpo de la guerra, "Encuesta de prevalencia de violencia sexual en contra de las mujeres en el contexto del conflicto armado colombiano 2010-2015", http:// humanidadvigente.net/wp-content/uploads/2017/08/Encuesta-de-prevalencia-de-violencia-sexual-CSCG. pdf (acceso octubre 5, 2018). 
Para hacer una comparación en el mismo período se accedió a la página de la Unidad de Víctimas, sin información sobre la institución o instancia a la cual acudieron las mujeres víctimas (Tabla 2).

Tabla 2. Información de mujeres con y sin discapacidad víctimas de violencia sexual. Reporte de los años 2010-2015

\begin{tabular}{|c|c|c|c|}
\hline Mujeres víctimas & Con discapacidad & Sin discapacidad & Total \\
\hline Año de declaración & $\$ 66.795$ & $\$ 1.339 .148$ & $\$ 1.405 .943$ \\
\hline 2010 & $\$ 5.109$ & $\$ 162.187$ & $\$ 167.296$ \\
\hline 2011 & $\$ 4.379$ & $\$ 147.312$ & $\$ 151.691$ \\
\hline 2012 & $\$ 14.023$ & $\$ 227.861$ & $\$ 241.884$ \\
\hline 2013 & $\$ 14.805$ & $\$ 286.353$ & $\$ 301.158$ \\
\hline 2014 & $\$ 15.586$ & $\$ 278.816$ & $\$ 294.402$ \\
\hline 2015 & $\$ 12.893$ & $\$ 236.619$ & $\$ 249.512$ \\
\hline $\begin{array}{c}\text { Víctimas reconocidas } \\
\text { Sentencia C-280 de 2013 }\end{array}$ & $\$ 3.805$ & $\$ 94.479$ & $\$ 98.284$ \\
\hline Auto 119 de 2013 & $\$ 168$ & $\$ 7.007$ & $\$ 7.175$ \\
\hline 2010 & $\$ 401$ & $\$ 14.585$ & $\$ 14.986$ \\
\hline 2011 & $\$ 615$ & $\$ 11.873$ & $\$ 12.488$ \\
\hline 2013 & $\$ 793$ & $\$ 17.676$ & $\$ 18.469$ \\
\hline 2014 & $\$ 959$ & $\$ 21.330$ & $\$ 22.289$ \\
\hline 2015 & $\$ 869$ & $\$ 22.008$ & $\$ 22.877$ \\
\hline Total & $\$ 70.600$ & $\$ 1.433 .627$ & $\$ 1.504 .227$ \\
\hline
\end{tabular}

Fuente: elaboración propia con datos del Registro único de víctimas

En estas cifras se evidencia una constante del delito de violencia sexual contra mujeres en condición de discapacidad.

En el posconflicto se hace necesario que las entidades que tienen a su cargo la sistematización de las variables en la información no solo visibilicen la dimensión el delito, sino también el actor que lo cometió, para que de esa manera, en el actual contexto, se enrostre el grado de impunidad ante los delitos y se evidencie el papel de la justicia. 


\section{Debida diligencia del Estado colombiano}

La Declaración sobre la eliminación de la violencia contra la mujer exhorta a los Estados a: "Proceder con la debida diligencia a fin de prevenir, investigar y, conforme a la legislacion nacional, castigar todo acto de violencia contra la mujer, ya se trate de actos perpetrados por el Estado o por particulares". ${ }^{18}$

De igual manera, el Sistema Interamericano de Derechos Humanos ha enfatizado en la responsabilidad internacional que les compete a los Estados frente a la inobservancia de la debida diligencia. ${ }^{19}$ Así lo respalda la Corte Interamericana de Derechos Humanos:

En efecto, un hecho ilícito violatorio de los derechos humanos que inicialmente no resulte imputable directamente a un Estado, por ejemplo, por ser obra de un particular o por no haberse identificado al autor de la trasgresión, puede acarrear la responsabilidad internacional del Estado, no por ese hecho en sí mismo, sino por falta de la debida diligencia para prevenir la violación o para tratarla en los términos requeridos por la Convención. ${ }^{20}$

En términos generales, con base en la debida diligencia, el Estado debe ejercer la autoridad soberana, prevenir y sancionar la violencia en contra de la mujer, para garantizar la protección judicial, amparar a la sociedad y lograr el fortalecimiento y la consolidación de lo que constituye un real Estado de derecho.

\section{Obstáculos en el camino a la justicia}

De acuerdo con la Declaración universal de los derechos humanos: "Toda persona tiene derecho a un recurso efectivo ante los tribunales nacionales competentes, que la ampare contra actos que violen sus derechos fundamentales reconocidos por la constitución o por la Ley". ${ }^{21}$

18 Organización de Naciones Unidas [ONU]. "Convención sobre la eliminación de todas las formas de discriminación contra la mujer", art. 4, num. c, https://www.oas.org/dil/esp/Convencion_sobre_todas_las_formas_de_Discriminacion_contra_la_Mujer.pdf (acceso junio 20, 2014).

19 Ana María Navarrete Frías, "La responsabilidad del Estado y su adecuación a parámetros interamericanos", Revista Estudios Socio-Jurídicos 11, núm. 2 (2009): 336.

20 Corte Interamericana de Derechos Humanos. Caso Velásquez Rodríguez Vs. Honduras. Sentencia del 29 de julio de 1998.

21 Organización de Naciones Unidas [ONU], Declaración universal de los derechos humanos (París, 10 de diciembre de 1948), art. 8. 
Debe garantizarse este derecho humano a la mujer en igualdad de condiciones como garantía de un servicio público, así como: "Adaptar todas las medidas adecuadas, incluso de carácter legislativo, para modificar o derogar leyes, reglamentos, usos y prácticas que constituyan discriminación contra la mujer". ${ }^{22}$

Esto significa para el Estado propender por eliminar todas las barreras que impidan el acceso de las mujeres a la justicia en un plano de igualdad.

Pese a lo anterior, uno de los principales obstáculos para el acceso de la justicia es la desigualdad entre los sexos, lo que formenta la falta de acceso de las mujeres a entornos provistos de oportunidades para la garantía de sus derechos. Esa desigualdad tiene aún más arraigo cuando existen factores sociales y culturales ${ }^{23}$ que conceden funciones a cada género y, de acuerdo con esa asignación, también se establecen derechos.

La Declaración sobre la eliminación de la violencia contra la mujer, aprobada por la ONU y la Convención de Belem do Pará advierten que la violencia sexual en contra de la mujer, además de ser una grave violación a los derechos humanos, refleja también relaciones asimétricas de poder entre hombres y mujeres.

También existen problemas por insuficiencia de mecanismos que garanticen el pleno ejercicio de los derechos consagrados en el derecho nacional; muestra de ello es la Sentencia T- 973 de 2011, que ilustra algunos obstáculos del acceso de una persona en condición de discapacidad víctima de violencia sexual: en el fallo de primera instancia se precluyó la investigación por la ausencia de testimonio de la afectada, pese al grado de vulnerabilidad e indefensión de la agredida. Este fallo lo confirmó la segunda instancia, decisión que la Corte Constitucional consideró reprochable por cuanto no se examinaron las pruebas en conjunto, lo que hubiera llevado a proferir sentencia condenatoria.

Todos estos hechos se agudizan cuando se trata de mujeres en condición de discapacidad que han sido víctimas de violencia sexual en el marco del conflicto

ONU, "Convención sobre la eliminación de todas las formas de discriminación contra la mujer", art. 2, lit. f. 23 María Isabel Afanador Contreras y María Claudia Caballero Badillo, "La violencia sexual contra las mujeres. Un enfoque desde la criminología, la victimología y el derecho", Reflexión Política 14, núm. 27 (2012): 125. 
armado, como lo muestra el Quinto informe de seguimiento al Auto 092 de la Corte Constitucional. ${ }^{24}$

A ello se suma la desconfianza por parte de las mujeres hacia el Estado y sus instituciones, pues los casos de violencia sexual relacionada con los conflictos no se denuncian debido a varios factores, por ejemplo, la percepción de que hacerlo resulta inútil, dada la:

[...] debilidad de la administración de justicia, entre otras; sumado a lo anterior existen normas culturales que prevalecen sobre las leyes escritas en los que la carga de prueba recae sobre la víctima; además del lento ritmo sobre las investigaciones, por falta de conocimientos especializados, por falta de voluntad o por falta de capacidad. ${ }^{25}$

Por otra parte, el hecho de que las mujeres deban convivir con sus victimarios incrementa su silencio y sus temores, lo que agrava las condiciones a las que son sometidas. Este panorama se agudiza por el entorno económico que las rodea $^{26} \mathrm{y}$, en el caso específico de discapacidad, esta condición se encuentra ligada a altos índices de pobreza y exclusión, así como a las falencias en los procesos de investigación de violencia sexual, ${ }^{27}$ pues hay "retrasos injustificados en las diligencias necesarias por parte de las instancias encargadas de efectuar la investigación y se presentan vacíos e irregularidades en las diligencias per se que obstaculizan el proceso de juzgamiento y la sanción eventual de los casos". ${ }^{28}$ En Colombia se presentan graves afectaciones para la población en condición de discapacidad, la cual se convierte en un obstáculo adicional a los que ya experimentan las mujeres, a causa de la "violencia de género, cuyos efectos se manifiestan en esta población a través de un mayor índice de crímenes violentos

24 Mesa de seguimiento al Auto 092 de la Corte Constitucional, Acceso a la justicia para mujeres víctimas de violencia sexual. Quinto informe de seguimiento al Auto 092 de 2008 de la Corte Constitucional, anexo reservado (Bogotá: Antropos, 2013), 25.

25 Organización de Naciones Unidas [ONU], "Violencia sexual relacionada con los conflictos. A/66/657S/2012/33", http://www.un.org/es/globalissues/women/informe2012.pdf (acceso octubre 5, 2018).

26 Ivonne Wilches, "Lo que hemos aprendido sobre la atención a mujeres víctimas de violencia sexual en el conflicto armado colombiano", Revista de Estudios Sociales, núm. 36 (2010): 88

27 Francisco Javier León Correa, "Pobreza, vulnerabilidad y calidad de vida en América Latina. Retos para la bioética", Acta Bioethica 17, núm. 1 (2011): 21.

28 Comisión Interamericana de Derechos Humanos, "Acceso a la justicia para mujeres víctimas de violencia en las Américas". 
y sexuales cometidos contra ellas, violencia machista, abortos coercitivos, esterilizaciones forzadas, trata de mujeres, entre otros". ${ }^{29}$

Es preciso analizar el acceso a la justicia como acceso a un sistema procedimental que pasa por el reconocimiento de garantías fundamentales, traducidas en el conocimiento de la verdad, la respuesta oportuna por parte de la justicia, un recurso judicial efectivo, la reparación integral por el daño causado y la restitución de los derechos, bajo el amparo de un trato digno, igualitario y no discriminatorio.

\section{Impunidad, indicador de un problema}

El concepto de justicia tiene dos dimensiones: ${ }^{30}$ una, referida al derecho humano fundamental de acceso a la justicia para recibir una respuesta eficaz y garantista acerca de sus derechos y, la segunda, respecto a la acción efectiva de la justicia para cada caso, por la cual se espera que el Estado, mediante su aparato judicial, adelante de forma oportuna, efectiva y diligente las investigaciones tendientes a endilgar las responsabilidades pertinentes a los culpables.

Sin embargo, la inacción, la indiferencia, la ausencia de garantías de justicia, la falta de acciones para efectivizar la verdad y la reparación y las limitaciones de acceso a la justicia debido a obstáculos impuestos por los operadores judiciales, se convierten en un escenario que siembra desconfianza en la mujer víctima de violencia sexual. Al respecto, el Centro Nacional de Memoria Histórica menciona:

La impunidad generalmente va acompañada de un gran desgaste emocional y del empobrecimiento ocasionado por la deficiente atención por parte del Estado o la limitada o nula reparación. La ausencia de instituciones idóneas, y en general, la falta de credibilidad en las Entidades del Estado ha incrementado la desconfianza de las víctimas. Las víctimas reclaman ser asumidas, defendidas y atendidas como ciudadanas, pues tienen claro que su experiencia es causa y consecuencia de la fragilidad de la democracia. ${ }^{31}$

29 Alta Consejería Presidencial para la Equidad de la Mujer, Observatorio de Asuntos de Género, "Mujer y discapacidad en Colombia", http://www.equidadmujer.gov.co/oag/Documents/oag-boletin-14-mujer-y-discapacidad-en-colombia.pdf (acceso junio 20, 2014).

30 Instituto Nacional de Derechos Humanos, "Situación de derechos humanos en Chile", http://www.corteidh. or.cr/tablas/29228.pdf (acceso julio 12, 2014).

31 Centro Nacional de Memoria Histórica, iBasta ya! Colombia: memoria de guerra y dignidad (Bogotá: Autor, 2013), 71 . 
Asimismo, la carencia de una real dimensión de género que impacte en políticas de reparación, una adecuada y proporcional tipificación nacional de la violencia sexual y la falta de documentación acerca de los hechos ${ }^{32}$ son factores que impiden el esclarecimiento y sanción del crimen de violencia sexual. ${ }^{33}$

Aunado a ello, la ausencia de denuncia acrecienta la impunidad. ${ }^{34} \mathrm{La}$ administración de justicia está llamada a contribuir con planes y estrategias que brinden una solución para que las mujeres víctimas pongan en conocimiento de las autoridades los delitos de los cuales han sido objeto, sin discriminación ni revictimización.

En el Anexo reservado del Auto 092, la Corte Constitucional puso en evidencia ante la Fiscalía General dos hechos acaecidos en contra de una mujer afrocolombiana con discapacidad cognitiva, pues en Sentencias T-973 de 2011 y T-595 de 2013, la Corte tuvo que pronunciarse para proteger su derecho de acceder a la justicia.

Otro agravante que se suma a la impunidad tiene que ver con la situación de invisibilidad e indiferencia. En el Informe sobre Colombia para el examen periódico universal sobre los derechos humanos de las personas con discapacidad se concluye que:

No existe un enfoque diferencial de discapacidad dentro de instituciones como la Fiscalía General de la Nación, el Instituto de Medicina Legal, la Defensoría y demás instituciones responsables del acceso a la justicia de personas con discapacidad en especial cuando se trata de violencia sexual contra personas con discapacidad. ${ }^{35}$

El alto índice de impunidad alerta acerca de la revisión de las decisiones por parte del aparato judicial y evidencia la vulnerabilidad y desprotección de

32 Stefannia Parrado, "Cuerpos dolientes: sobre la reparación en mujeres indígenas víctimas de violencia sexual en el conflicto armado colombiano", Revista Universidad Distrital 7, núm. 1 (2014): 46.

33 Lina María Céspedes Báez, "La violencia sexual en contra de las mujeres como estrategia de despojo de tierras en el conflicto armado colombiano", Revista Estudios Socio-Jurídicos 12, núm. 2 (2010): 286.

34 Claudia Cecilia Ramírez, Arañando la justicia. Violencia sexual e impunidad en el conflicto armado en Colombia (Bilbao: Hegoa, 2008), 15-16.

35 Organización de Naciones Unidas [ONU], "Informe para el Examen Periódico Universal sobre los derechos humanos de las personas con discapacidad en Colombia", http://ib.ohchr.org/HRBodies/UPR/Documents/ Session16/CO/JS2_UPR_COL_S16_2013_JointSubmission2_S.pdf (acceso 6 de julio de 2014). 
las mujeres en condición de discapacidad, por lo que se requieren cambios fundamentales del sistema de justicia.

\section{La continuidad de la violencia sexual en época de paz}

Elisabeth Jean Wood afirma:

[...] los patrones de violencia sexual en tiempos de paz y de guerra se diferencian en magnitud, pero no en su tipo [...] un vínculo adicional entre la violencia sexual asociada al conflicto y la violencia en la posguerra tiene que ver con la recurrencia del conflicto: períodos de paz después de guerras civiles tienen 3,5 mayor probabilidad de terminar en conflicto nuevamente en zonas con altas tasas de violaciones asociadas al conflicto. ${ }^{36}$

Dadas las cifras sobre violencia sexual que manejan algunas entidades del Estado, se advierte que esta clase de violencia podría mantenerse en esta nueva etapa de "paz" en Colombia, sobre todo en las zonas donde se crean los programas de desarrollo con enfoque territorial (PDET), que incluyen territorios de pueblos y comunidades étnicas y otros con presencia de grupos étnicos, en los 170 municipios designados mediante el Decreto 893 de 2017. ${ }^{37}$

"La violencia contra las mujeres por su carácter estructural y sistémico no cesa en los contextos de post-conflicto, a menos que haya claras señales de deslegitimación de estas prácticas". ${ }^{38}$

\section{Acciones de algunas instituciones del Estado y cifras}

Durante el primer semestre de 2018 se elevaron varios derechos de petición a los cuales respondieron:

Elisabeth Jean Wood, "La violencia sexual asociada al conflicto y las implicaciones políticas de investigaciones recientes", Estudios Socio-jurídicos 18, núm. 6 (2016): 23, 26.

37 Por el cual se crean los programas de desarrollo con enfoque territorial PDET.

38 Corporación Humanas Chile, "Sin tregua. Políticas de reparación para mujeres víctimas de violencia sexual durante dictaduras y conflictos armados", http://www.humanas.cl/wp-content/uploads/2014/publicaciones/03\%20sin\%20tregua\%202008.pdf (acceso octubre 5, 2018). 
La Consejería Presidencial para los Derechos Humanos ${ }^{39}$ informa que desarrolla diferentes acciones y estrategias relacionadas para la prevención y lucha contra la impunidad de las violencias de género, en especial de las violencias sexuales, mediante diversas estrategias.

El Ministerio de Justicia y del Derecho ${ }^{40}$ informa que lidera la estrategia de acceso a la justicia a mujeres y población con orientaciones sexuales e identidades de género diversas, víctimas de violencia sexual en el marco del conflicto armado, hoy denominada RedConstruyendo. Además, indica que, de acuerdo con el reporte de la Unidad para las Víctimas, a "corte del 1 de marzo de 2018, 8.064 mujeres con discapacidad han sido registradas como víctimas del conflicto armado interno". ${ }^{41}$ De acuerdo con este referente, la Dirección de Justicia Transicional del Ministerio de Justicia adelanta la construcción de lineamientos técnicos para la incorporación del enfoque diferencial en la atención de las personas con discapacidad víctimas del conflicto.

La Unidad para la atención y reparación integral a las víctimas informa que "los datos y en general la información propia de su competencia, se encuentra disponible para consulta en la página web". ${ }^{42}$

Por otra parte, para revisar el comportamiento de la violencia sexual en los departamentos en los cuales se crearon los programas de desarrollo con enfoque territorial (PDET), se presentan a continuación las estadísticas de violencia. Se tuvieron en cuenta como fuentes de información: i) los reportes de la página web de la Unidad de Víctimas (Tabla 3):

\footnotetext{
Derecho de Petición EXT18-00023852

Respuesta a Derecho de petición EXT18-0010445

Respuesta a Derecho de petición EXT18-0010445.

2 Respuesta a Derecho de petición 20187115747542.
} 
Tabla 3. Delitos contra la integridad sexual. Mujeres en condición de discapacidad

\begin{tabular}{|c|c|c|c|c|c|}
\hline Año & Municipio & $\begin{array}{c}\text { Entre } 18 \text { y } 28 \\
\text { años }\end{array}$ & $\begin{array}{c}\text { Entre } 29 \text { y } 60 \\
\text { años }\end{array}$ & $\begin{array}{c}\text { Entre } 61 \text { y } 100 \\
\text { años }\end{array}$ & Total general \\
\hline \multirow{38}{*}{2015} & Acevedo & 1 & & & 1 \\
\hline & Almaguer & & 1 & & 1 \\
\hline & Amalfi & & 1 & & 1 \\
\hline & Argelia & & 1 & & 1 \\
\hline & Balboa & & 1 & & 1 \\
\hline & Buenaventura & 1 & 2 & & 3 \\
\hline & Buesaco & & 1 & & 1 \\
\hline & Cajibío & & 1 & & 1 \\
\hline & Caldono & & 1 & & 1 \\
\hline & Cali & & 2 & & 2 \\
\hline & Caloto & & & 1 & 1 \\
\hline & Chigorodó & 1 & 2 & & 3 \\
\hline & Cumbitara & & 1 & & 1 \\
\hline & Dabeiba & 1 & & & 1 \\
\hline & Dibulla & & 1 & & 1 \\
\hline & El Bagre & 1 & & & 1 \\
\hline & El Carmen de Bolívar & & 1 & 1 & 2 \\
\hline & El Colegio & & 1 & & 1 \\
\hline & El Litoral del San Juan & & & 1 & 1 \\
\hline & Hacarí & & 1 & & 1 \\
\hline & Medio Atrato & 1 & 4 & 1 & 6 \\
\hline & Nuquí & & 1 & 1 & 2 \\
\hline & Piendamó & 1 & & & 1 \\
\hline & Plato & & 1 & & 1 \\
\hline & Policarpa & & 1 & & 1 \\
\hline & Pueblo Rico & & 1 & & 1 \\
\hline & Puerto Asís & 1 & & & 1 \\
\hline & Puerto Rico & & 1 & & 1 \\
\hline & Quibdó & 1 & 2 & & 3 \\
\hline & San Andrés de Tumaco & & 3 & & 3 \\
\hline & San José del Guaviare & & 1 & & 1 \\
\hline & San Miguel & 3 & & & 3 \\
\hline & San Vicente del Caguán & 1 & & & 1 \\
\hline & Segovia & & 2 & & 2 \\
\hline & Solano & & 1 & & 1 \\
\hline & Suárez & & 1 & & 1 \\
\hline & Villagarzón & & 1 & & 1 \\
\hline & Vistahermosa & 1 & & & 1 \\
\hline
\end{tabular}




\begin{tabular}{|c|c|c|c|c|c|}
\hline Año & Municipio & $\begin{array}{c}\text { Entre } 18 \text { y } 28 \\
\text { años }\end{array}$ & $\begin{array}{c}\text { Entre } 29 \text { y } 60 \\
\text { años }\end{array}$ & $\begin{array}{c}\text { Entre } 61 \text { y } 100 \\
\text { años }\end{array}$ & Total general \\
\hline \multirow{37}{*}{2016} & Algeciras & & 1 & & 1 \\
\hline & Amalfi & & 1 & & 1 \\
\hline & Apartadó & 1 & 1 & & 2 \\
\hline & Armenia & & 1 & & 1 \\
\hline & Balboa & & 1 & & 1 \\
\hline & Barbacoas & & 1 & & 1 \\
\hline & Belén de los Andaquíes & & & 1 & 1 \\
\hline & Buenaventura & & 1 & & 1 \\
\hline & Cali & 1 & & & 1 \\
\hline & Chaparral & & 1 & & 1 \\
\hline & Ciénaga & 1 & & & 1 \\
\hline & Colón & & 1 & & 1 \\
\hline & Coyaima & & & 1 & 1 \\
\hline & Cumaribo & 1 & & & 1 \\
\hline & Curillo & 1 & & & 1 \\
\hline & Dibulla & & 1 & & 1 \\
\hline & El Tambo & & 1 & & 1 \\
\hline & Florencia & & 1 & & 1 \\
\hline & Florida & & 2 & & 2 \\
\hline & Guapi & & 1 & & 1 \\
\hline & Ibagué & & 2 & & 2 \\
\hline & Istmina & 1 & 1 & & 2 \\
\hline & La Vega & 1 & & & 1 \\
\hline & Mapiripán & & 1 & & 1 \\
\hline & Medio Baudó & & 1 & & 1 \\
\hline & Morales & & & 1 & 1 \\
\hline & Neiva & 1 & & & 1 \\
\hline & Quibdó & & 2 & & 2 \\
\hline & Quimbaya & 1 & & & 1 \\
\hline & San Andrés de Tumaco & 1 & 2 & & 3 \\
\hline & San José del Fragua & & 1 & & 1 \\
\hline & San Marcos & & 1 & & 1 \\
\hline & San Pablo & & 1 & & 1 \\
\hline & Santa Rosa del Sur & 1 & & & 1 \\
\hline & Teorama & & 1 & & 1 \\
\hline & Timbío & & 1 & & 1 \\
\hline & Valle del Guamuez & & 1 & & 1 \\
\hline
\end{tabular}




\begin{tabular}{|c|c|c|c|c|c|}
\hline Año & Municipio & $\begin{array}{c}\text { Entre } 18 \text { y } 28 \\
\text { años }\end{array}$ & $\begin{array}{c}\text { Entre } 29 \text { y } 60 \\
\text { años } \\
\end{array}$ & $\begin{array}{c}\text { Entre } 61 \text { y } 100 \\
\text { años } \\
\end{array}$ & Total general \\
\hline \multirow{13}{*}{2017} & Cali & 1 & & & 1 \\
\hline & La Vega & 1 & & & 1 \\
\hline & López & 1 & & & 1 \\
\hline & Neiva & & 1 & & 1 \\
\hline & Palmira & & 1 & & 1 \\
\hline & Puerto Leguízamo & & 1 & & 1 \\
\hline & Roldanillo & & 1 & & 1 \\
\hline & San Andrés de Tumaco & 1 & & & 1 \\
\hline & San José del Fragua & & & 1 & 1 \\
\hline & San Vicente Del Caguán & 1 & & & 1 \\
\hline & Sandoná & 1 & & & 1 \\
\hline & Tamalameque & 1 & & & 1 \\
\hline & \multicolumn{4}{|l|}{ Total } & 113 \\
\hline
\end{tabular}

\begin{tabular}{|c|c|c|c|c|c|}
\hline $\begin{array}{c}\text { Año de } \\
\text { ocurrencia }\end{array}$ & Departamento & \begin{tabular}{|c|} 
Entre 18 y 28 \\
años
\end{tabular} & \begin{tabular}{|c|} 
Entre 29 y 60 \\
años \\
\end{tabular} & $\begin{array}{l}\text { Entre } 61 \text { y } \\
100 \text { años }\end{array}$ & Total general \\
\hline \multirow{17}{*}{2015} & Antioquia & 3 & 6 & & 9 \\
\hline & Bolívar & & 1 & 1 & 2 \\
\hline & Caquetá & 1 & 2 & & 3 \\
\hline & Cauca & 1 & 5 & 1 & 7 \\
\hline & Chocó & 2 & 7 & 3 & 12 \\
\hline & Cundinamarca & & 1 & & 1 \\
\hline & Guaviare & & 1 & & 1 \\
\hline & Huila & 1 & & & 1 \\
\hline & La Guajira & & 1 & & 1 \\
\hline & Magdalena & & 1 & & 1 \\
\hline & Meta & 1 & & & 1 \\
\hline & Norte de Santander & & 1 & & 1 \\
\hline & Nariño & & 6 & & 6 \\
\hline & Putumayo & 1 & 1 & & 2 \\
\hline & Risaralda & & 1 & & 1 \\
\hline & Santander & 3 & & & 3 \\
\hline & Valle del Cauca & 1 & 4 & & 5 \\
\hline Total 2015 & & 14 & 38 & 5 & 57 \\
\hline
\end{tabular}




\begin{tabular}{|c|c|c|c|c|c|}
\hline $\begin{array}{c}\text { Año de } \\
\text { ocurrencia }\end{array}$ & Departamento & \begin{tabular}{|c|} 
Entre 18 y 28 \\
años \\
\end{tabular} & \begin{tabular}{|c} 
Entre 29 y 60 \\
años \\
\end{tabular} & $\begin{array}{c}\text { Entre } 61 \mathrm{y} \\
100 \text { años } \\
\end{array}$ & Total genera \\
\hline \multirow{17}{*}{2016} & Antioquia & 1 & 3 & & 4 \\
\hline & Bolívar & 1 & 1 & 1 & 3 \\
\hline & Caquetá & 1 & 2 & 1 & 4 \\
\hline & Cauca & 1 & 4 & & 5 \\
\hline & Chocó & 1 & 4 & & 5 \\
\hline & Huila & 1 & 1 & & 2 \\
\hline & La Guajira & & 1 & & 1 \\
\hline & Magdalena & 1 & & & 1 \\
\hline & Meta & & 1 & & 1 \\
\hline & Norte de Santander & & 1 & & 1 \\
\hline & Nariño & 1 & 4 & & 5 \\
\hline & Putumayo & & 1 & & 1 \\
\hline & Quindío & 1 & & & 1 \\
\hline & Sucre & & 1 & & 1 \\
\hline & Tolima & & 3 & 1 & 4 \\
\hline & Valle del Cauca & 1 & 3 & & 4 \\
\hline & Vichada & 1 & & & 1 \\
\hline Total 2016 & & 11 & 30 & 3 & 44 \\
\hline \multirow{7}{*}{2017} & Caquetá & 1 & & 1 & 2 \\
\hline & Cauca & 2 & & & 2 \\
\hline & Cesar & 1 & & & 1 \\
\hline & Huila & & 1 & & 1 \\
\hline & Nariño & 2 & & & 2 \\
\hline & Putumayo & & 1 & & 1 \\
\hline & Valle del Cauca & 1 & 2 & & 3 \\
\hline Total 2017 & & 7 & 4 & 1 & 12 \\
\hline Total general & & 32 & 72 & 9 & 113 \\
\hline
\end{tabular}

Fuente: elaboración propia con datos del Registro único de víctimas

ii) El sistema penal oral acusatorio (SPOA) de la Fiscalía General de la Nación. Se tuvieron en cuenta los delitos bajo la variable de la Ley 906 de 2004; sin embargo, en este registro no es posible identificar las variables "conflicto armado" y las condiciones "discapacidad y género" (Tabla 4). 
Tabla 4. Reportes comportamiento violencia sexual SPOA, 2015-2017

\begin{tabular}{|c|c|c|c|c|}
\hline Departamento & 2015 & 2016 & 2017 & Total general \\
\hline Amazonas & 43 & 46 & 44 & 133 \\
\hline Antioquia & 1.900 & 1.418 & 1.392 & 4.710 \\
\hline Arauca & 74 & 53 & 71 & 198 \\
\hline $\begin{array}{l}\text { Archipiélago de San Andrés, } \\
\text { Providencia y Santa Catalina }\end{array}$ & 23 & 26 & 34 & 83 \\
\hline Atlántico & 528 & 380 & 470 & 1.378 \\
\hline Bogotá, DC & 2.126 & 1.730 & 1.859 & 5.715 \\
\hline Bolívar & 530 & 499 & 475 & 1.504 \\
\hline Boyacá & 390 & 304 & 329 & 1.023 \\
\hline Caldas & 242 & 196 & 190 & 628 \\
\hline Caquetá & 96 & 98 & 97 & 291 \\
\hline Casanare & 128 & 83 & 98 & 309 \\
\hline Cauca & 412 & 392 & 413 & 1.217 \\
\hline Cesar & 237 & 245 & 251 & 733 \\
\hline Chocó & 127 & 110 & 110 & 347 \\
\hline Córdoba & 279 & 251 & 279 & 809 \\
\hline Cundinamarca & 741 & 687 & 746 & 2.174 \\
\hline Guainía & 22 & 16 & 28 & 66 \\
\hline Guaviare & 37 & 19 & 30 & 86 \\
\hline Huila & 307 & 325 & 328 & 960 \\
\hline La Guajira & 131 & 83 & 131 & 345 \\
\hline Magdalena & 234 & 215 & 239 & 688 \\
\hline Meta & 263 & 268 & 311 & 842 \\
\hline Nariño & 613 & 538 & 492 & 1.643 \\
\hline Norte de Santander & 215 & 184 & 215 & 614 \\
\hline Putumayo & 133 & 95 & 100 & 328 \\
\hline Quindío & 111 & 95 & 122 & 328 \\
\hline Risaralda & 236 & 204 & 185 & 625 \\
\hline Santander & 612 & 519 & 545 & 1.676 \\
\hline Sucre & 216 & 166 & 183 & 565 \\
\hline Tolima & 601 & 428 & 472 & 1.501 \\
\hline Valle del Cauca & 1.134 & 951 & 980 & 3.065 \\
\hline Vaupés & 16 & 17 & 26 & 59 \\
\hline Vichada & 17 & 7 & 10 & 34 \\
\hline Total general & 12.774 & 10.648 & 11.255 & 34.677 \\
\hline
\end{tabular}

Fuente: elaboración propia con datos de la Fiscalía General de la Nación (SPOA) 
Las cifras muestran que la violencia sexual en contra de las mujeres continúa y se intensifica, sobre todo en las zonas más afectadas por el conflicto armado.

Vale la pena analizar si durante la época de posconflicto se hace una real transición o si lo que sucede es que hay una renovación de agresores, por cuanto siguen perpetrándose formas de control territorial basadas en la violencia sexual. Frente a ello se hace imperioso tomar medidas adecuadas y oportunas para evitar que se prolonguen los riesgos para las mujeres en condición de discapacidad y que la paz no signifique un cambio para ellas.

\section{Conclusiones}

La violencia sexual ha afectado de manera significativa a la población en condición de discapacidad y ante ese panorama es preciso evidenciar el desamparo que las mujeres han vivido en la cultura patriarcal colombiana.

Dados los Acuerdos de paz, el Estado debe adoptar con eficacia el papel como garante y asumir la protección que se deriva de su rol, además de generar medidas con un enfoque holístico e interdisciplinario que provean soluciones positivas y efectivas incluso para personas en condición de discapacidad.

Pese a que hay instituciones que se encuentran implementando estrategias en favor de las mujeres en condición de discapacidad, persiste la falta de información en los registros que dé cuenta de la realidad.

La etapa del posconflicto actual exige abogar por un sistema que cumpla su misión y sea capaz de equilibrar la necesidad de complementar los ejercicios de justica punitiva con elementos de justicia restaurativa, para entregarles a las víctimas el reconocimiento suficiente, en el que la sociedad civil que ha sido agraviada desempeñe un papel activo.

Respecto a las estadísticas y al subregistro documentado por autores y organizaciones gubernamentales y no gubernamentales hace falta claridad en la información y generar conciencia en los operadores judiciales por medio de la adopción de mecanismos de atención eficaz y pertinente que eliminen las dificultades de acceso. 
Se mantiene la esperanza de que en época de posconflicto no prevalezca la violencia sexual, porque el país no puede seguir tolerándola. Ya han sido demasiados los sufrimientos que una población tan vulnerable como las mujeres en condición de discapacidad han tenido que padecer.

\section{Referencias}

Abramovich, Víctor. "De las violaciones masivas a los patrones estructurales: nuevos enfoques y clásicas tensiones en el Sistema Interamericano de Derechos Humanos". Derecho PUCP 63 (2009): 95-138. http://revistas.pucp.edu.pe/index.php/derechopucp/article/ download/2961/2863 (acceso octubre 15, 2014).

Afanador Contreras, María Isabel y María Claudia Caballero Badillo. "La violencia sexual contra las mujeres. Un enfoque desde la criminología, la victimología y el derecho". Reflexión Política 14, núm. 27 (2012): 122-133.

Alta Consejería Presidencial para la Equidad de la Mujer, Observatorio de Asuntos de Género. "Mujer y discapacidad en Colombia". http://www.equidadmujer.gov.co/ oag/Documents/oag-boletin-14-mujer-y-discapacidad-en-colombia.pdf (acceso junio 20, 2014).

Arroyo Vargas, Roxana. "Acceso a la justicia para las mujeres... El laberinto androcéntrico del derecho". Revista IIDH 53 (2011): 35-62. http://www.corteidh.or.cr/tablas/r26673. pdf (acceso mayo 5, 2014).

Barbero, Natalia. "Los derechos humanos de la mujer y la violencia sexual en el derecho internacional". Principia Iuris 17, núm. 17 (2012): 329-353.

Barragán Ávila, Fanny y Martha Alfonso. "Lineamientos de política pública para la prevención, protección, atención y sanción de las violencias basadas en género y contra las mujeres en Colombia". http://historico.equidadmujer.gov.co/Normativa/ PoliticaPublica/LineamientosPolitica.pdf (acceso junio 7, 2014).

Campaña Violaciones y otras violencias: saquen mi cuerpo de la guerra. "Encuesta de prevalencia de violencia sexual en contra de las mujeres en el contexto del conflicto armado colombiano 2010-2015". http:/humanidadvigente.net/wp-content/uploads/2017/08/ Encuesta-de-prevalencia-de-violencia-sexual-CSCG.pdf (acceso octubre 5, 2018).

Centro Nacional de Memoria Histórica. iBasta ya! Colombia: memoria de guerra y dignidad. Bogotá: Autor, 2013.

Céspedes Báez, Lina María. "La violencia sexual en contra de las mujeres como estrategia de despojo de tierras en el conflicto armado colombiano". Revista Estudios Socio-Jurídicos 12, núm. 2 (2010): 273-304. 
Comisión Interamericana de Derechos Humanos. "Acceso a la justicia para mujeres víctimas de violencia en las Américas". https://www.cidh.oas.org/pdf\%20files/Informe\%20 Acceso\%20a\%20la\%20Justicia\%20Espanol\%20020507.pdf (acceso agosto 1, 2014). Corporación Humanas Chile. "Sin tregua. Políticas de reparación para mujeres víctimas de violencia sexual durante dictaduras y conflictos armados". http://www.humanas.cl/ wp-content/uploads/2014/publicaciones/03\%20sin\%20tregua\%202008.pdf (acceso octubre 5, 2018).

Corporación Humanas. Aportes para el acceso a la justicia de las mujeres en Colombia. Bogotá: Antropos, 2011.

Corporación Sisma Mujer. "Obstáculos para acceso a la justicia de las mujeres víctimas de violencia sexual en Colombia”. http://www.sismamujer.org/wp-content/uploads/2016/12/33.Obst\%C3\%Alculos-de-Acceso-a-Justicia-de-Mujeres-V\%C3\%ADctimas-de-ViolenciaSexual-en-Colombia.pdf (acceso agosto 2, 2014).

Corte Interamericana de Derechos Humanos. Caso Velásquez Rodríguez Vs. Honduras. Sentencia del 29 de julio de 1998.

Declaración universal de los derechos humanos. París, 10 de diciembre de 1948.

Ferrer Araujo, Nina. "El acceso a la justicia como elemento indispensable del ejercicio de la ciudadanía femenina”. Opinión Jurídica 9, núm. 17 (2010): 113-124.

Franco Moreno, Sandra Milena y Marlings Eugenia Garcés Ballesteros. "Políticas de equidad para las mujeres víctimas de violencia en Santander". Revista al derecho y al revés 8 (2013): 57-70. http://publicaciones.unisangil.edu.co/index.php/revista-derecho-reves/ article/download/35/39

Fundación Círculo de Estudios Culturales y Políticos Colombia, Defensoría del Pueblo y Organización Internacional para las Migraciones [OIM]. El papel del acceso a la justicia en la superación de la discriminación hacia las mujeres, los niños, las niñas y adolescentes. Bogotá: OIM, 2013.

Gobierno Nacional y Fuerzas Armadas Revolucionarias de Colombia-Ejército del Pueblo. "Acuerdo final para la terminación del conflicto y la construcción de una paz estable y duradera”. http://www.altocomisionadoparalapaz.gov.co/herramientas/Documents/ Acuerdo-Final-AF-web.pdf (acceso octubre 5, 2018).

Instituto Nacional de Derechos Humanos. "Situación de derechos humanos en Chile". http://www.corteidh.or.cr/tablas/29228.pdf (acceso julio 12, 2014).

León Correa, Francisco Javier. "Pobreza, vulnerabilidad y calidad de vida en América Latina. Retos para la bioética”. Acta Bioethica 17, núm. 1 (2011): 19-29.

Martínez Ríos, Beatriz. "Pobreza, discapacidad y derechos humanos". Revista Española de Discapacidad 1, núm. 1 (2013): 9-32. 
Mesa de seguimiento al Auto 092 de la Corte Constitucional. Acceso a la justicia para mujeres victimas de violencia sexual. Quinto informe de seguimiento al Auto 092 de 2008 de la Corte Constitucional, anexo reservado. Bogotá: Antropos, 2013.

Navarrete Frías, Ana María. "La responsabilidad del Estado y su adecuación a parámetros interamericanos". Revista Estudios Socio-Jurídicos 11, núm. 2 (2009): 335-376.

Organización de Estados Americanos [OEA]. "Las mujeres frente a la violencia y la discriminación derivadas del conflicto armado en Colombia”. http://www.cidh.org/ countryrep/colombiamujeres06sp/informe\%20mujeres\%20colombia\%202006\%20 espanol.pdf (acceso agosto 1, 2014).

Organización de Naciones Unidas [ONU]. "Convención sobre la eliminación de todas las formas de discriminación contra la mujer". https://www.oas.org/dil/esp/Convencion_sobre_todas_las_formas_de_Discriminacion_contra_la_Mujer.pdf (acceso junio 20, 2014).

Organización de Naciones Unidas [ONU]. "Informe para el Examen Periódico Universal sobre los derechos humanos de las personas con discapacidad en Colombia". http:// lib.ohchr.org/HRBodies/UPR/Documents/Session16/CO/JS2_UPR_COL_S16_2013_ JointSubmission2_S.pdf (acceso 6 de julio de 2014).

Organización de Naciones Unidas [ONU]. "Integración de los derechos humanos de la mujer y la perspectiva de género. Violencia contra la mujer. Informe de la relatora especial sobre la violencia contra la mujer, sus causas y consecuencias, Sra. Radhika Coomarasswam, presentado de conformidad con la resolución 2001/49 de la Comisión de Derechos Humanos. Adición. Misión a Colombia (1 a 7 de noviembre de 2001)". http://www.hchr.org.co/documentoseinformes/documentos/html/informes/onu/ resvm/E-CN-4-2002-83-Add3.html (acceso agosto 1 de 2014).

Organización de Naciones Unidas [ONU]. "Violencia sexual relacionada con los conflictos. A/66/657-S/2012/33". http://www.un.org/es/globalissues/women/informe2012.pdf (acceso octubre 5,2018 ).

Parrado, Stefannia. "Cuerpos dolientes: sobre la reparación en mujeres indígenas víctimas de violencia sexual en el conflicto armado colombiano". Revista Universidad Distrital 7, núm. 1 (2014): 24-47.

Quinn, Gerard y Theresia Degener. "Derechos humanos y discapacidad. Uso actual y posibilidades futuras de los instrumentos de derechos humanos de las Naciones Unidas en el contexto de la discapacidad". http://repositoriocdpd.net:8080/bitstream/handle/123456789/614/L_QuinnG_DerechosHumanosDiscapacidad_2002. pdf?sequence $=1$ (acceso agosto 2, 2014).

Ramírez, Claudia Cecilia. Arañando la justicia. Violencia sexual e impunidad en el conflicto armado en Colombia. Bilbao: Hegoa, 2008. 
Ribotta, Silvia. "Reglas de Brasilia sobre acceso a la justicia de las personas en condición de vulnerabilidad. Vulnerabilidad, pobreza y acceso a la justicia". Ponencia presentada en la XIV cumbre judicial iberoamericana, Brasilia, 4 a 6 de marzo, 2008.

Wilches, Ivonne. "Lo que hemos aprendido sobre la atención a mujeres víctimas de violencia sexual en el conflicto armado colombiano". Revista de Estudios Sociales, núm. 36 (2010): 86-94.

Wood, Elisabeth Jean. "La violencia sexual asociada al conflicto y las implicaciones políticas de investigaciones recientes”. Estudios Socio-jurídicos 18, núm. 6 (2016): 13-46. 


\section{Anexo 1}

Respuesta al derecho de petición EXT18-00023852

\section{Respuesta solicitud EXT18-00023852}

Marjorle lsabel Vizcalno Fontalvo <marjorievizcaino@presidencia.gov.co> 23

Señora

ALEXANDRA CHAPARRO LOPEZ

Peticionaria

Respetada Señora Chaparro,

Hemos recibido su comunicación, radicada bajo el No. EXT18-00023852 en la que nos solicita información respecto a la garantia de los derechos de la población de mujeres en condición de discapacidad, en especial, victimas del conflicto armado.

Le informamos que la Consejeria Presidencial para los Derechos Humanos trabaja, desde el Gobiemo Nacional, en la elaboración y coordinación de las politicas públicas entorno a los Derechos Humanos y Derecho Internacional Humanitario (DIH).

A través del Sistema Nacional de Derechos Humanos y DIH-SNDDHH, creado mediante el Decreto 4100 del 2 de noviembre de 2011 , la Consejería coordina e impulsa las acciones dirigidas a la promoción, protección y defensa de los derechos humanos, con las diferentes entidades gubernamentales que tienen competencia en la materia. Entre las principales acciones de la entidad, se vela por la garantia y goce efectivo de los derechos humanos de toda la población, la lucha contra la impunidad, la consolidación del Sistema Nacional de Derechos Humanos y DIH, la promoción de una cultura en derechos humanos y el fortalecimiento, tanto de las relaciones con las organizaciones de la sociedad civil, como de los vínculos de cooperación con los organismos internacionales.

En desarrollo de los objetivos trazados en el marco del SNDDHH se diseñó la "Estrategia Nacional para la Garantia de los Derechos Humanos 2014 - 2034" como una hoja de ruta institucional para la promoción y protección de los $\mathrm{DDHH}$ y una respuesta del Estado a la sociedad civil y a la comunidad internacional sobre la incorporación de los resultados del proceso de construcción participativa de una politica integral en esta materia. 
Entre los principios rectores de la Estrategia Nacional se encuentra el de Igualdad y No Discriminación, el cual establece que: todos los individuos son iguales como seres humanos en virtud de la dignidad inherente de toda persona. Todos los seres humanos tienen derechos sin discriminación de ninguna clase por vaza, color, sexo, etnia, edad, idioma religión opinión política o de otra indole, origen nacional o social, discapacidad, propiedad, nacimiento u otra condición, según ha sido explicado por los órganos de vigilancia de los tratados de derechos humanos.

De tal manera que se transveroaliza el enfoque diferencial en la Fatrategia Nacional. En particular, se resalta las acciones del Subistema de Igualdad y No Discriminación sobre la materia, ejemplo: Estrategia 5.2. Impulsar y fortalecer las medidas necesarias para garantizar el goce $y$ ejercicio en igualdad de condiciones, de los derechos y libertades de las personas con discapacidad Para mayor información, por favor consultar el siguiente link: http://www.derechoshumanos.gov.co/Observatorio/Publicaciones/Documen ts/2014/140815-estrategia web.pdf

Las acciones concretas a favor de la población en situación de discapacidad son lideradas en su implementación por las entidades competentes en la materia. En este sentido, resaltamos el trabajo que adelanta el Ministerio de Salud con la adopción de la Resolución 1904 de 2017 del Ministerio de Salud en cumplimiento de lo ordenado por la Sentencia T-573 de 2016 de la Corte Constitucional en materia de Derechos Sexuales y Reproductivos.

En materia de conflicto armado, la Unidad para la Atención y Reparación Integral a las Victimas en el marco del Subcomité de Enfoque diferencial- Decreto 4800 de 2011, y el Ministerio de Justicia-Dirección de Justicia Transicional en materia del enfoque diferencia de personas en condición de discapacidad victimas del conflicto armado para el acceso a la justicia. Entidades couien sugerimos consultar sobre los avances en materia.

Por otro ladn _. La Consejeria Presidencial para los Derechos Humanos desarrolla diferentes acciones y estrategias relacionadas para la prevención, $y$ lucha contra la impunidad de las violencias de género, en especial, de las violencias sexuales, que a continuación se relacionan:

\section{Estrategia RedConstouxendo para la Garantia de los Derechos de las Mujeres}

Esta Estrategia se inicia a implementar en 2017, de la suma de los aprendizajes y esfuerzos que a nivel nacional se han adelantado, en años anteriores, en materia de | 
prevención de las violencias de género en el marco del conflicto armado, la atención integral y la judicialización de los hechos, tales como:

- Estrategia interinstitucional de acceso a la justicia a mujeres y personas con orientaciones sexuales e identidades de género diversas sobrevivientes de violencia sexual (Liderada por el Ministerio de Justicia)

- Estrategia de Lucha contra la Impunidad de las Violencias basadas en género en el marco del conflicto armado, en especial, víctimas de violencia sexual (Liderada por la Consejería Presidencial para la Equidad de la Mujer, Consejeria para los Derechos Humanos y la Fiscalia General de la Nación).

Esta unión de esfuerzos busca el uso eficiente de los recursos que se tiene para la atención de las mujeres sobrevivientes y el fortalecimiento de las capacidades institucionales para la prevención, atención, y protección de las VBG en el marco del conflicto armado, y un mayor impacto a nivel territorial.

La Estrategia tiene tres componentes de trabajo: i. Fortalecimiento a organizaciones de mujeres; ii. Fortalecimiento de las capacidades institucionales del nivel local; iii. Seguimiento a casos.

Respecto al trabajo con las organizaciones de mujeres, se trabajan tres ejes: - Nivel Personal (Cuidado Emocional e identificación de redes de afecto y apoyo), Nivel comunitario y colectivo: (i. Fortalecimiento en conocimiento de derechos, liderazgos para el matconflictos y participación ciudadana); nivel económico: Identificación de redes de recursos para el fortalecimiento económico. Estos ejes recogen propuestas y situaciones que plantean las mujeres en las regiones.

La Estrategia está dirigida a que lideresas y organizaciones de mujeres sobrevivientes del conflicto conozcan sus derechos, identifiquen las violencias basadas en género y ge apropien de herramientas para incidir en instancias de toma de decisiones.

De igual manera, se busca fortalecer las capacidades territoriales de los funcionarios públicos con asistencia técnica para la prevención y atención de las VBG y en el trabajo de la transformación de imaginarios y actitudes que contribuyan a una mejor atención de las victimas. A su vez, se abren espacios de dialngn entre las mujeres lideresas de la zona, y la institucionalidad local para la construcción de confianzas.

2. Estrategia Interinstitucional e Intercultural para el abordaje integral de la violencia sexual y de género contra niños, niñas, adolescentes y mujeres indigenas.| 
La Consejería para los Derechos Humanos y el Instituto Colombiano de Bienestar Familiar ejercen la Secretaría Técnica de esta Estrategia, en la que también participan la Consejeria Presidencial para la Equidad de la Mujer, Ministerio de Justicia, Instituto Nacional de Medicina Legal, Ministerio del Interior, Fiscalia General de la Nación, Ministerio de Educación, Ministerio de Salud, Consejo Superior de la Judicatura, ONIC, OPLAC, UNICEF y UNFPA. Esta iniciativa tiene como objetivo generar acciones de articulación y armonización entra la institucionalidad y los pueblos indigenas, orientadas al abordaje integral de la violencia de género, con énfasis en violencia sexual, contra niños, niñas, mujeres y comunidades indigenas.

En el marco de este proceso se adelantan las siguientes acciones: i. sensibilización y formación dirigidas a funcionarios públicos, organizaciones y autoridades indigenas, niños, niñas, mujeres que se orienten a la prevención, atención y protección integral de las víctimas de violencia sexual y de género al interior de las comunidades indigenas; ii. Fortalecimiento al liderazgo de las mujeres indigenas para la protección de las familias y comunidades y rutas de acceso a la justicia; iii. Acciones de sensibilización a funcionarios públicos acerca de los derechos humanos de los pueblos indigenas y su reconocimiento como administradores de la justicia propia; iv. Desarrollo de metodologías para diseño de rutas de atención al interior de los pueblos indigenas que participa; v. Generar propuestas de articulación local e interjurisdiccional en la que además de realizar acuerdos de trabajo en temas de acceso a la justicia, se logre la articulación de las rutas de atención a la violencia sexual al interior de comunidades indigenas, tanto institucionales como comunitarias. En este marco, se ha entablado escenarios de articulación con el Consejo Superior de la Judicatura, en donde se ha visibilizado la problemática de acceso a la justicia a víctimas de violencia sexual al interior de los pueblos indigenas y se han socializado recomendaciones a autoridades indigenas para el abordaje de estos casos en articulación con la justicia ordinaria. 


\section{Anexo 2}

Respuesta al derecho de petición EXT18-0010445

Bogotá D.C., 27 de marzo de 2018

Señora

Alexandra Milena Chaparro López

Calle 57 No 77 C 26 Casa 107 Barrio Villa Luz Bogota D.C.

Asunto: Respuesta Derecho de Petición

MINISTERIO DE JUSTICIA Y DEL DERECHO

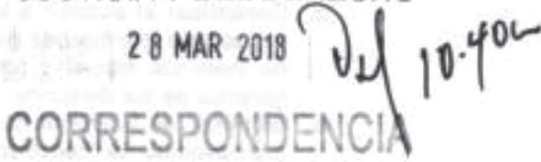

Respetada señora Chaparro.

En atencion a su solicitud radicada en esta entidad con EXT18-0010445 de fecha 13 de marzo del presente aగ̆o, atentamente damos respuesta a petición, en la cual solicita: " (...) información respecto a programas o acciones que desamolla su entided incorporado el enfoque diferencial de mujer y discapacidad (...):

Al respecto, me permito hacer las siguientes precisiones:

1. Acciones desarrolladas donde se incorpora el enfoque diferencial de mujer y discapacidad en el marco del conflicto armado y postconflicto.

1.1 RedConstruyendo- Estrategia territorial para el acceso a la iusticia de grupos poblacionales diferenciales victimas de violencia sexual $\mathrm{y}$ otras violencias basadas en género en el marco del conflicto armado

El Ministerio de Justicia y del Derecho, a través de la Dirección de Justicia transicional, lidera la estrategia de Acceso a la Justicia a mujeres y población con orientaciones sexuales e identidades de género diversas victimas de violencia sexual en el marco del conflicto armado, hoy denominada RedConstruyendo. La secretaria técnica de esta estrategia se ejerce en conjunto entre la Consejeria Presidencial de Derechos Humanos, La Consejeria para la Equidad de la Mujer y el Ministerio de Justicia y en una alianza con la Fiscalla General de la Nación, el Ministerio Publico, la Unidad para la Atención y Reparación Integral a Victimas del Conflicto Armado, los entes territoriales y el apoyo de la Cooperación internacional.

Mediante esta iniciativa las victimas se acercan a los procesos judiciales y administrativos vigentes para la atención y protección de sus derechos mediante el conocimiento de las rutas de acceso existentes, para lo cual se facilita a la victimas en los lugares de origen su participación a través de jornadas de denuncia penal y declaración, proporcionándoles además toda la información sobre el estado de su proceso de atención y reparación y la respuesta local de acuerdo a los programas sociales a su cargo.

$$
\text { Bogotó D.C., Colombia }
$$

Colle 53 No. 13-27 • Teléfono (57) (1) 4443100 • www.minjusticia.gov.co 
Esta estrategia tiene un carácter territorial puesto que las entidades participantes se acercan a las comunidades de victimas en sus lugares de asentamiento, apoyan a las organizaciones de mujeres y de grupos de población diferenciales para lograr el empoderamiento en su condición de sujetos de derecho y de actores de incidencia en la politica pública local de victimas.

De manera concreta, lo objetivos de la estrategia son los siguientes:

a. Garantizar el acceso a la justicia para las mujeres, personas con orientaciones sexuales e identidades de género diversas y otros grupos poblacionales victimas de violencia sexual y otras violencias basadas en género, para contribuir a la garantia de los derechos.

b. Eliminar las barreras de acceso a la justicia y atención integral a nivel local, promoviendo la construcción de relaciones de confianza para garantizar los derechos.

c. Identificar los avances y retos en el seguimiento de los compromisos pactados y recomendaciones realizadas en las zonas en las que se ha implementado la estrategia.

d. Fortalecer en temas de derechos humanos y exigibilidad de derechos a mujeres y personas con orientaciones sexuales e identidades de género diversas victimas de violencia sexual y violencia basada en genero dentro y fuera del marco del conflicto armado, lideres, lideresas y organizaciones de base.

e. Prestar asistencia técnica a las autoridades locales para la articulación interinstitucional en la debida atención integral a mujeres victimas y acceso a la justicia.

f. Fortalecer a mujeres victimas, lideresas $y$ organizaciones de mujeres y personas con orientaciones sexuales $e$ identidades de genero diversas para la incidencia ante las autoridades locales en la debida atención y acceso a la justicia.

g. Facilitar la apropiación de herramientas para la transformación de las afectaciones psicosociales causadas por la violencia sexual y otras violencias basadas en genero.

h. Contribuir a la reducción de sub-registro y al impulso judicial de los casos de violencia sexual y otras violencias basadas en género.

\section{Componentes de la Estrategia}

A partir de las experiencias y lecciones aprendidas, la estrategia cuenta con un modelo de trabajo interinstitucional que se describe en el siguiente cuadro:

La Estrategia tiene tres componentes de trabajo: i. Fortalecimiento a organizaciones de mujeres; ii. Fortalecimiento de las capacidades institucionales del nivel local; ii. Seguimiento a casos.

Respecto al trabajo con las organizaciones de mujeres, se trabajan tres ejes: Nivel Personal (Cuidado Emocional e identificación de redes de afecto y apoyo): Nivel comunitario y colectivo (fortalecimiento en conocimiento de derechos, liderazgos para el postconflictos y participación ciudadana) y nivel económico (identificación de redes de

$$
\text { Bogotá D.C., Colombia }
$$

Calle 53 No. 13-27 • Teléfono (57) (1) 444,3100 • uww.minjusticia-gov.co 
O) Minuusticia

Este proyecto se implementó, con un primer piloto realizado durante el segundo semestre (en el mes de Noviembre de 2017). Este piloto se realizó con ANMUCIC Nacional, en la ciudad de Bogotá. El segundo proceso de talleres se implementó en la ciudad de Quibdó (y contando con la participación de mujeres de la Red Departamental de mujeres Chocoanas, la Ruta Pacifica del Chocó, Cocomacia - Comisión de Género y ANMUCiC).

1.4 Lineamientos técnicos para la incorporación del enfoque diferencial en la atención de las personas con discapacidad victimas del conflicto

Según el reporte de la Unidad para las Victimas, a corte de 1 de marzo del 2018, 8064 mujeres con discapacidad han sido registradas como victimas en el marco del conflicto armado interno. Lo mencionado es tan solo uno de los referentes que han fundamentado que desde la Dirección de Justicia Transicional, del Ministerio de Justicia y del Derecho. se construyan lineamientos técnicos para la incorporación del enfoque diferencial en la atención de las personas con discapacidad victimas del conflicto. Sin embargo, desde el 2017 y durante lo corrido del 2018 la construcción e implementación de estos lineamientos se ha constituido como todo un proceso de sensibilización en el que han participado entidades e instituciones estatales ( 30 aprx.), organizaciones de victimas con discapacidad ( 300 personas aproximadamente) y funcionarios de las estrategias de acceso a la justicia para sobrevivientes de violencia sexual (Redconstruyendo) y Unidad Movil (15 personas entre funcionarios y contratistas). Estos escenarios de sensibilización han permitido la toma de conciencia en la adopción de las obligaciones juridicas que tiene el estado colombiano, de respetar y velar por el goce de todos los derechos humanos por parte de las personas con discapacidad en igualdad de condiciones (NNA, adultos, adulto mayor, mujeres, grupos étnicos, personas con orientaciones e identidades sexuales diversas), como parte esencial en la construcción de paz.

\subsection{Mesa de Sequimiento al Auto 173 de 2014}

La Dirección de Justicia Transicional también adelanta actividades de interlocución con otras entidades para garantizar los derechos de personas en situación de discapacidad.

Cabe mencionar a este respecto que la Corte Constitucional expidio el Auto 173 de 2014. el cual hace seguimiento a las ordenes proferidas por la Corte Constitucional en el Auto 006 de 2009 sobre protección de las personas en situación de desplazamiento con discapacidad, (esto, en el marco del estado de cosas inconstitucional declarado en la sentencia T-025 de 2004). Asi mismo, en dicho Auto la Corte adopta "medidas para garantizar la toma de decisiones con apoyo de las personas con discapacidad en situación de desplazamiento forzado'. Para el adelanto de estas medidas, la Corte conminó a la UARIV, al Ministerio de Justicia y el Derecho, la Procuraduria General de la Nación y a la Defensoria del Pueblo para desarrollar "mecanismos idóneos para garantizar el igual reconocimiento de las personas con discapacidad ante la ley Bogotó D.C., Colombia

Calle 53 No. 13-27 • Teléfono (57) (1) 4443100 • www.minjusticia.gov.co 


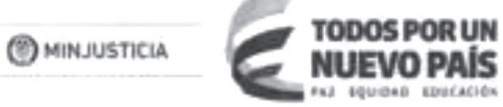

especialmente aquellas con discapacidades mentales- y el ejercicio de su capacidad juridica en los términos del articulo 12 de la CDPD*.

Con el fin de darle cumplimiento a esta orden, las entidades conminadas crearon la Mesa Técnica del Auto 173 de 2014 , la cual se encarga de hacer seguimiento a las medidas adoptadas por las mismas que garanticen los derechos de las personas en situación de discapacidad victimas del conflicto armado. El Ministerio de Justicia y el Derecho, a través de la Dirección de Justicia Transicional, detenta la secretaria técnica de esta Mesa.

Durante el año 2017, la Mesa se reunió en dos ocasiones. Ambas estuvieron orientadas a dos asuntos: Primero, preparar la presentación del informe de seguimiento al Auto 173 de 2014 a la Corte Constitucional y, segundo, realizar conjuntamente una gran capacitación sobre atencion a personas en situación de discapacidad en el mes de septiembre de 2017. Esto, con el fin de que los distintos esfuerzos que adelantan las entidades de manera independiente en materia de formación, puedan confluir en un único esfuerzo cualificado y riguroso.

\section{Información estadística sobre la población en condición de discapacidad.}

En el marco de la Estrategia Unidad Móvil se han atendido a 3170 personas en condición de discapacidad, de los cuales 1773 fueron hombres y 1397 mujeres.

En el marco de la Estrategia de acceso a la justicia- RedConstruyendo a continuación se relacionan los resultados obtenidos de las jornadas de declaración y denuncia. La información no se encuentra desagregada por personas en condición de discapacidad atendidas.

- Acciones dirigidas a las mujeres.

Desde mayo de 2015 hasta diciembre de 2017, se han realizado 15 jornadas en 6 departamentos del pais y Bogotá. En este periodo han participado 716 mujeres victimas de violencia sexual en el marco del conflicto armado y otras violencias basadas en género. Asi mismo, se han recepcionado 657 declaraciones como victimas y 626 denuncias.

Desde la gestion de fortalecimiento, 7 organizaciones de mujeres han participado en acciones de empoderamiento y liderazgo, y se apoyado el proceso de reparación colectiva a dos sujetos de reparación colectiva, la Organización Femenina Popular OFP Y LA Asociación Nacional de Mujeres Campesinas, Negras e Indigenas de Colombia ANMUCIC

Por otra parte, la estrategia incorpora el enfoque psicosocial y el enfoque diferencial de manera transversal a todas sus actividades, en este contexto, en octubre de 2016 se inicio un trabajo en conjunto con ONUMujeres, la Organización Nacional Indigena de Bogotá D.C., Colombia

Calle 53 No. $13-27$ • Teléfono (57) (1) 4443100 • www.minjusticia.gov.co 
OMinJusticia

\section{TODOS POR UN NUEVO PAIS}

Colombia- ONIC y la Asociación Mujeres El Plantón, para desarrollar lineamientos del componente étnico en la estrategia, lo cual permitio el desarrollo de acciones de atención con enfoque étnico a 67 mujeres Embera Katio de las comunidades de Polines, Guapa Alto, Saundo-Jurado y Chigorodocito, de los resguardos de Polines y Yaverarando, del cabildo de Chigorodó-Antioquia.

Las acciones implementadas y los resultados obtenidos en esta estrategia se sintetizan en la tabla descrita a continuación:

ESTRATEOA FECONSTMLTENDO

RESUE TADOS JORWADAS DE DECLARAOON Y DENUNCAA 2015-2017

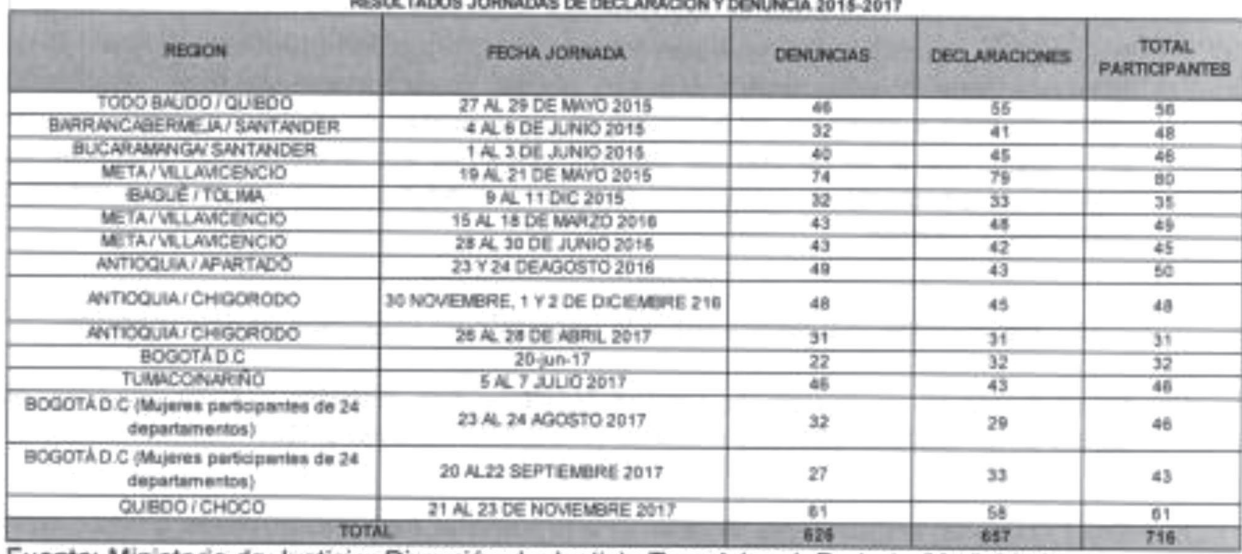

Fuente: Ministerio de Justicia- Dirección de Justicia Transicional, Periođo 2015-2017

- Acciones con población LGBTI

Durante el 2015 se inició la estrategia de acceso a la justicia para población con orientaciones sexuales e identidades de género diversas, victimas de violencia sexual en el marco del conflicto armado, con quienes se realizaron 19 círculos de acompañamiento psicosocial en Tumaco, Barranquilla, Quibdó y Pasto con la participación de aproximadamente 100 miembros de esta comunidad. En el afto 2016 se desarrollaron 3 procesos de acceso a la justicia en Quibdo. Villavicencio y Barranquilla atendiendo a 66 personas, obteniendo 55 denuncias del hecho de violencia sexual y 42 declaraciones en su condición de víctimas.

En el 2017 en alianza con la Consejería Presidencial de Derechos Humanos, teniendo en cuenta las condiciones especiales de inseguridad, actores armados por fuera de la ley. violencia y presencia de comunidades negras en el Municipio de Tumaco, ubicado en la zona del pacifico Colombiano, asi como las barreras geograficas, se adelanto una actuación especial que dio como resultado la participación en el mes de octubre de 49 personas LGBT, y la toma de 46 denuncias y 45 declaraciones En el mes de noviembre se realizo jornada de declaración y denuncia en la ciudad de Bogotá con personas

Bogotó D.C., Colombia

Calle 53 No. 13-27 • Teléfono (57) (1) 4443100 • www.minjusticia.gov.co 
OMinuUsticia

\section{TODOSPOR UN} NUEVO PAÍS

provenientes del Urabá Antioqueño, Putumayo y Tolima contando con la participación de 57 personas, se realizaron 49 denuncia y 53 declaraciones.

En el cuadro siguiente se detalla la gestión adelantada con esta población:

\begin{tabular}{|c|c|c|c|c|}
\hline Region & $\begin{array}{c}\text { Fecha Jornada } \\
\text { Declaracion y Denuncia }\end{array}$ & Denuncias & Declaraciones & $\begin{array}{c}\text { Total } \\
\text { Participantes }\end{array}$ \\
\hline Atlantico / Barranquila & 5 al 7 de julo de 2016 & 8 & 5 & 17 \\
\hline Chooo / Quibdo & 23 Y 24 DE MAYO 2016 & 31 & 30 & 32 \\
\hline Vilavicencio / Meta & 27 y 28 de Octubre de 2016 & 16 & 7 & 17 \\
\hline Tumaco / Narino & 13 al 17 de Octubre 2017 & 46 & 45 & 49 \\
\hline $\begin{array}{c}\text { Bogota (Personas } \\
\text { provenientes del Uraba } \\
\text { Antioqueho, Putumayo y } \\
\text { Tolima) }\end{array}$ & 28 al 30 Noviembre 2017 & 49 & 53 & 57 \\
\hline \multicolumn{2}{|c|}{ TOTAL } & 150 & 140 & 172 \\
\hline
\end{tabular}

Fuente: Minsterio de Justicia-Dirección de Justicia Transicional, Periodo 2016-2017

Estos procesos descentralizados e interinstitucionales dan respuesta efectiva al derecho de información y atención inmediata de las victimas para conocer sus demandas. inquietudes, garantizar la puerta de entrada al sistema de atención mediante la declaración como victima. Asi mismo, han facilitado la respuesta institucional inmediata y su enrutamiento al proceso de reparación integral.

3. Seguimiento frente a las acciones que se derivan de la gestión y que son competencia de otras entidades estatales.

La estrategia RedConstruyendo busca, además de contribuir a la visibilización de la problemática de violencia sexual en el conflicto armado, incidir efectivamente en el impulso judicial de los procesos que se activen con la interposición de las denuncias realizadas en el marco de la implementación de la estrategia. De igual modo, estar al tanto de la materialización efectiva de la reparación para estas victimas.

A su turno, la interposición de las denuncias penales y la consecuente activación de un proceso judicial, requiere necesariamente el seguimiento a las denuncias que se recolecten, con el fin de impulsar de manera efectiva la impartición de justicla en esos casos. Asi, las entidades que hacen parte de la estrategia, deberán facilitar el seguimiento y monitoreo de los avances del proceso judicial y de reparación, implementando buenas prácticas en materia de gestión de la información relacionada con la estrategia.

Frente a lo anterior se han realizado las siguientes acciones:

- Encuentros de retroalimentación

Bogołó D.C., Colombia

Calle 53 No. 13.27 • Teléfono (57) (1) 4443100 • www.minjusticia.gov.co 
En el año 2015 se realizaron 11 encuentros de retroalimentación con las mujeres de Magdalena. Sucre, Atlántico, Choco Norte de Santander, Valle del Cauca, Cesar, Guajira, Cauca, Estos encuentros tenian como objetivo de resolver las dudas grupales e individuales de las mujeres frente a los procesos de declaración yio denuncia. En ellos participaban la Fiscalia General de la Nación con un representante, la Defensoria del Pueblo con Delegados de la defensoria pública y la Unidad para las Victimas con los orientadores.

- Fiscalia General de la Nación

- Unidad para las Victimas

- Secretaria de salud de la Gobernación del Meta

- Superintendencia de Salud.

> Disefo e implementación de formatos de recolección y organización de la información:

En el año 2016 se diseño e inició la implementación de formatos en Excel que permitieran ordenar la información existente. Igualmente se disef̂aron e implementaron formatos fisicos para que la nueva información del proceso de acceso a la justicia fuese captada de forma sistemática permitiendo generar análisis de trazabilidad de las acciones realizadas en los momentos del proceso en especial en la jornada de declaración y denuncia.

> Plan de seguimiento año 2016:

Los encuentros de retroalimentación mostraron la necesidad de generar un plan de seguimiento que en primera medida generara una base en la que se consolidaran la información organizada, depurada y actualizada de todas las mujeres que han participado en la estrategia para con ella iniciar dentro de las entidades competentes una revisión del estado de sus procesos, y con esto realizar un diagnóstico que permitiese identificar el real avance de los casos tanto en lo relativo a justicia como en lo correspondiente a reparación integral e identificar las posibles barreras que puedan estar generando retrasos en los procesos.

El plan de seguimiento planteado en el 2016 constaba de 4 fases:

1. Depuración de las bases de datos de forma tal que se pueda tener certeza frente a la veracidad de los nombres y números de cédula.

2. Cruce de información con la Fiscalia General de la Nación y la Unidad Para las Victimas.

3. Retroalimentación a los participantes de la estrategia del resultado del cruce de información por dos vias; telefónica y presencial a través del desarrollo de encuentros con fin de generar un acercamiento directo entre la institucionalidad y los participantes en el cual se logre en estos últimos generar un mayor conocimiento de las rutas en general y en sus procesos en particular para dar continuidad al proceso de restablecimiento de confianza victimas institucionalidad y empoderamiento de las victimas.

$$
\text { Bogolá D.C., Colombia }
$$

Calle 53 No. 13-27 • Telêfono (57) (1) 4443100 • www.minjusticia.gov.co 
OPMinusticia

4. Incidencia con las entidades competentes con el fin de aportar herramientas, documentos, informes y otros elementos que permitan aportar al avance significativo de los procesos que facilitan el goce efectivo de los derechos a la verdad, la justicia y la reparación integral a los participantes de la estrategia.

Acciones 2017

El 21 de junio de 2017 se llevó a cabo en Villavicencio - Meta el momento de seguimiento con 27 mujeres de municipios del bajo ariari en el departamento del Meta, las cuales han participado en la estrategia de acceso a la justicia a sobrevivientes de violencia sexual en los años 2015-2016. El objetivo de este taller fue dar información actualizada y personalizada frente al avance de sus denuncias, del proceso de declaración y ofrecer el acceso a las medidas de salud.

La implementación de la estrategia RedConstruyendo como proceso de fortalecimiento de capacidades y liderazgos de las mujeres contó con la participación sistemática en las tres regiones, Quibdó- Choco, Agustin Codazzi - Cesar y Florencia- Caquetá de 110 mujeres, la mayoria integrantes de organizaciones de mujeres o de procesos sociales como Juntas de Acción Comunal, mesa de victimas, entre otros. El reconocimiento de las organizaciones de mujeres y sus iniciativas de articulación en el territorio fue muy importante porque posibilitó una participación más cualificada de las mujeres y su apropiación del conocimiento con interés de replicar con las integrantes de sus organizaciones, lo cual amplia el impacto que pueda tener la estrategia en cada región.

En referencia al punto tres y cuatro según su petición, se corrió traslado por competencia mediante OFI18-0009061-DJT-3100 OFI18-0009062-DJT-3100, OFI18-0009063-DJT3100, y OFI18-0009064-DJT-3100, a Fiscalia General de la Nación, Policia Nacional, Unidad para las Victimas y Ministerio de Salud, respectivamente, para los fines que estime pertinente.

Finalmente, en cuanto a la cita que se va a concertar si asi lo estima pertinente, esta puede ser concretada con la funcionaria Laura Sofia Céspedes, quien está encargada de la coordinación de la Estrategia de Acceso a la Justicia-RedConstruyendo a la dirección de correo electrónico laurasofiaces dit.minjusticia@agmail.com o al teléfono (1) 4443100 ext 1621 .

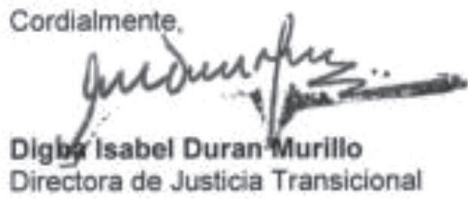

Anexos: 4 folios

Flobard Laura Cadena.

Reried: Laura Cespedes.

Aprobs: isabel Duran.

Bogotá D.C., Colombia

Calle 53 No. 13.27 • Teléfono (57) (1) 4443100 • www.minjusticia.gov.co 


\section{Anexo 3}

Respuesta al derecho de petición 20187115747542

(9) UNIDAD PARA LAS victimas

\section{GOBIERNO DE COLOMBIA}

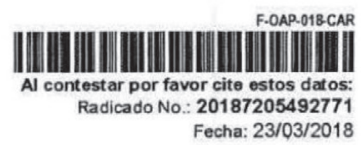

Bogotá D.C

Señora

ALEXANDRA MILENA CHAPARRO LOPEZ

ALEXANDRACHAPARROL@GMAIL.COM

BOGOTA D, C.

20187205492771

TELEFFONOS: 2222800 EXTENSION 5535 - 3194818910

Asunto: Respuesta a derecho de petición radicado No 20187115747542

Código LEX: 2918608

D.1 \#: 52336353

En atención a su solicitud radicada ante la Unidad para las Victimas, nos permitimos informar. SOLICITUD DE INFORMACION:

En respuesta a su comunicación radicada, donde solicita información de personas victimas de la violencia, la Unidad para las Victimas se permite informarle que:

Los datos y en general la información piopia de nuestra competencia, se encuentra para consulta pública en la página de la Unidad para las Victimas en la dirección http://rni.unidadvictimas.gov. co ingresando al link reportes, en tal ubicación Usted podrá consultar información agregada a nivel nacional, departamental, territorial y municipal de las personas que están incluidas en el Registro Único de Victimas. Adicionalmente puede filtrarse por ubicación, hecho victimizante, enfoque diferencial (género, étnica, ciclo vital) y años de ocurrencia o ceclaración de los hechos.

Ahora bien, en procura de que se amplié la información y con el fin de proteger el derecho a la intimidad de las victimas y su seguridad, cordialmente le solicitamos nos indiqué cual va a ser la finalidad y uso de la misma, ya que la información que reposa en la Entidad es de carácter reservado, según el Parágrafo $1^{\circ}$ del Artículo 156 de la Ley 1448 y por lo tanto se limita su acceso a terceros.

En la Unidad para las Victimas es muy importante tener actualizados sus datos de contacto, asi como la informacion del Registro Único de Victimas - RUV, por esto le invitamos a informar cualquier modificación a través de nuestros canales de atención.

Para la Unidad para la Atención y Reparación Integral a las Victimas, es importante contar con su opinión para mejorar nuestros servicios de atención al usuario. Para ello lo(a) invitamos a responder la encuesta de satisfaccion que se encuentra en la página web https://www.unidadvictimas.gov.co/es/encuesta-de-satisfaccion/37436, le agradecemos su participación.

Atentamente,

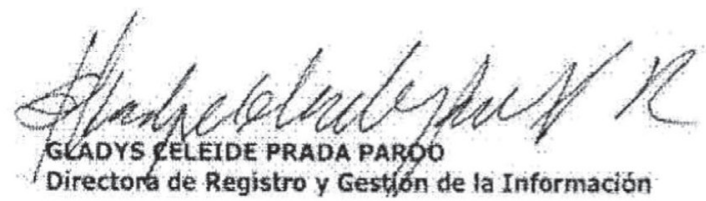

Analizó y Proyecto: HEIDI G_(GRE - PQR - LEX) 